\title{
The impact of cyberbullying and cyber harassment on academic achievement
}

\author{
Gunstein Egeberg, Steinar Thorvaldsen, John A. Rønning
}

UIT - The Arctic University of Norway

\begin{abstract}
Cyberbullying is commonly measured by either an inventory of manifest variables (i.e. cyber harassment) or the use of global items covering cyberbullying in general. This study aimed to compare these two approaches in terms of how they predict academic achievement. Structural equation modelling (SEM) was used to build recursive models including variables of academic achievement, traditional and cyber harassment, cyberbullying, socio-economic status, perceived quality of life at school, and sex. Our findings reveal an impact of cyberbullying and cyber harassment on academic skills, and furthermore suggest that the choice of method (manifest variables vs. global items) is of less importance in this regard. Furthermore, the impact of cyberbullying and cyber harassment on academic achievement appears to be mainly mediated through the victims' perceived quality of life at school.
\end{abstract}

\section{Background}

Bullying is often seen as a subcategory of peer aggression. Three criteria distinguish bullying from other kinds of aggression: imbalance of power, repetition or duration of negative actions and a deliberate will to hurt. Research was initially directed towards physical and verbal forms of harassment (Olweus, 2001, Heinemann, 1973, Olweus, 1978). Social, or indirect, forms of bullying were identified in the eighties (Lagerspetz et al., 1988). In the 2000s, digital bullying, more usually expressed as "cyberbullying", was identified (Campbell, 2005, Smith et al., 2006).

Some researchers have addressed the impact of bullying on academic achievement, but findings differ. Glew et al. (2005) found that victims and bully-victims (students who are involved as both bullies and victims) scored lower on measures of academic achievement. Their findings were significant even though the reported odds ratios indicate rather low effects (OR=0.8-0.9). Woods and Wolke (2004) found no effect of direct bullying, either as victim or bully, on academic achievement for students in grades 2 and 4 . In the case of indirect bullying, no effect was found for victims, but they identified indirect (or relational) bullies as performing better academically. As they did for other influences on academic achievement, they reported such effects for wellknown variables such as special educational needs, socioeconomic status, rural schools and small classes. Strøm et al. (2013) found negative effects of bullying on grades at both student and school level. Being subject to bullying is associated with lower academic achievement, but even attending schools with high levels of bullying has a negative impact on grades. Strøm et al. (2013) found that being exposed to more than one type of violence (sexual abuse, violence inflicted by other youths or adults, or bullying) increased the negative impact on academic achievements. Kowalski and Limber (2013) found negative effects on academic achievements for both traditional forms of bullying and cyberbullying. The strongest effect was found for bully-victims, especially in the 
context of cyberbullying. In a meta-study of 25 reports, Tokunaga (2010) found that most researchers have identified effects of bullying on academic achievements, but he drew some very important conclusions: first, that definitional issues need to be dealt with further in order to provide better a foundation for empirical research. He also pointed to the lack of theory on cyberbullying and to the need for longitudinal data to deal with causation. Finally, he claimed that more sophisticated relationships in the context of cyberbullying need to be addressed. In other words, there is a lot to be done in the context of cyberbullying research.

The impact of socio-economic status (SES) on educational achievement is well known and has been studied for several decades. In one of the first large-scale studies of SES in the US, Sewell and Shah (1967) investigated several aspects of the impact of intelligence and SES on college plans, attendance and graduation. They found that both SES and intelligence had effects on these, but while the effect of SES was more dominant for females, the effect of intelligence was more dominant for males. The direct impact of SES on academic achievements was one of several important findings of the Coleman report on equality in education (Coleman et al., 1966). As pointed out by White (1982), SES became a very strong predictor of all kinds of effects in education. Even though there was consensus regarding the existence of the influence of SES, White noted that the size of the effect or the strength of relevant correlations varied a great deal. Importantly, the unit of analysis, either the student or a group (e.g. school), proved to play a very important role. In his meta-analysis, White concluded that utilizing SES to predict academic achievements where the student is the unit is problematic, due to the low impact of SES in this context (White, 1982). In more recent studies, Hattie found a moderately strong effect of SES on student achievement, and furthermore that there are only minor differences in the effect size of the three most frequently used SES measures: parental occupation, level of parental education and parental income (Hattie, 2008, p. 61). However, White (1982) identified more than 70 variables measuring SES, and the effect of SES on academic achievement sometimes greatly differed among these. In general, he found that the correlation of SES and academic achievement was at the 0.3level when the student was the unit of analysis. Marks, Cresswell and Ainley (2006) found that cultural factors of SES, measured in terms of the number of books and the presence of classical literature, poetry, and works of art in the home, were important elements of SES. It would thus appear to be necessary to control for SES when academic achievement is being measured, even though there are still unresolved issues regarding the impact and measurement of SES.

In many countries, boys face more problems in school than girls do, at least where overall academic performance is concerned (OECD, 2004, OECD, 2007, OECD, 2010, OECD, 2014, OECD/UNESCO, 2003) and involvement in bullying (Olweus, 1994, Smith and Gross, 2006, Juvonen et al., 2010, Wendelborg et al., 2014). However, there are important variations. For instance, in the reading tests in PISA (Programme for International Student Assessment of the OECD) boys perform consistently and considerably worse than girls, and the difference is actually greatest among poorly performing students. In mathematics, the picture is somewhat different. Boys tend to perform better than girls do, although the difference is clearly smaller than in reading. However, in mathematics the gender differences emerge among the highest performing students. The proportions of low-performing students are not very different between sexes, but more boys than girls perform at the highest level. PISA point to the challenge 
of improving boys' academic performance (OECD, 2014). In Norway girls outperform boys in all subject, except from physical education (Bakken et al., 2008). In the case of bullying, there is a general tendency for boys to be more involved both as bullies and victims at all ages (Wendelborg et al., 2014, Seals and Young, 2003, Erdur-Baker, 2010, Salmivalli and Nieminen, 2002)However, some researchers have found that girls are more involved in indirect or social bullying (Lagerspetz et al., 1988, Björkqvist et al., 1992), but this findings is not consistent (Craig et al., 2009). In the case of cyberbullying, no clear effect of either gender og age is found, although some findings suggest that that girls are more at risk of being targeted (Tokunaga, 2010). As far as age is concerned, there may exist curve linearity that shadows the effect.

Cyberbullying is defined by Olweus in terms similar to traditional bullying, with the distinction that it takes place via electronic means (Olweus, 2013). The application of the three crucial criteria of traditional bullying has been challenged by some researchers, on a number of grounds (Menesini and Nocentini, 2009). Repetition and duration are more difficult to assess online since, for instance, a picture might be posted once, but then be shared further by others. Power imbalance is also difficult as victims are often able to block people who are being mean. Anonymity also comes into play here, and this influences power imbalance as the perpetrator might well be in an inferior position physically or socially, but can remain unknown to the victim. It is not clear whether researchers should view cyberbullying as being very similar to traditional bullying, or if "cyber-aggression" (a broader term) would be a more suitable term (Livingstone and Smith, 2014). Grigg (2010) argues that a broader definition of bullying is needed in the case of cyberbullying. Kowalski et al. (2014) identified a number of personal and situational factors that come into play when children are involved in bullying. The interrelationships of these factors are rather complex.

Bullying is measured in different ways, the most common of which are probably selfreport questionnaires. Solberg and Olweus (2003) concluded that the single, global item "Have you been bullied the past two or three months?" is the best method. The item should be accompanied with a definition of bullying to guide the student. Five response categories are given: (never, only once, two or three times a month, about once a week and several times a week). Several studies have utilised this method to estimate prevalence (Smith and Gross, 2006, Stevens et al., 2000, Fekkes et al., 2004). There are however concerns about the validity of most bullying measurement instruments (Vessey et al., 2014), and criticism has been raised regarding the dominant method of self-report (Vivolo-Kantor et al., 2014). As pointed out by Kowlaski et al. (2014), some findings suggest that the use of the word "bullying" might decrease effect sizes as children might be less willing to admit to being bullied (as opposed to mere negative forms of behaviour). More work is needed to develop more accurate and valid instruments to capture bullying.

It is worth mentioning the commonly used regression techniques in research of prediction or causality in bullying research. Different regression techniques build upon specific assumptions concerning data. No measurement error, linearity between dependent and independent variables, multivariate normality, no outliers, homoscedasticity and no multicollinearity are some of the assumption that might apply to the various forms of regressions and ANOVAs. As many researchers have pointed out, the understanding of the term "bullying" differs substantially between various groups 
(e.g. age, country, etc) (Menesini et al., 2002, Smorti et al., 2003, Smith et al., 2002, Arora, 1996). There are strong indicators that many of the most frequently used approaches to capture bullying are fraught with measurement error. In order to deal with measurement error, some caution is needed when regression analysis in its various forms is employed (Siemsen et al., 2010, Cote and Buckley, 1987). As most bullying items are not normally distributed and probably have considerable amounts of measurement error, the choice of appropriate analysis is important.

Quality of life (QoL) is a measure of how persons experience their life at a given point. The measure is widely used in medicine as a means of assessing the impact of various diagnoses on patients' lives (Smith et al., 1999). QoL is not universally understood and defined, but Jozefiak (2009) defined QoL as "The subjective reported well-being in regard to the child's physical and mental health, self-esteem and perception of own activities (playing/having hobbies when the child is alone), the perceived relationship to friends and family as well to school and a global evaluation of QoL". An association between bullying and QoL has ben identified (Wilkins-Shurmer et al., 2003, Frisén and Bjarnelind, 2010)

\section{Assumptions and research questions}

Cyberbullying is a new field of research, and much remains to be done. So far, empirical findings and theories derived from traditional bullying research have been used to understand cyberbullying, but researchers disagree whether this transference holds. It appears obvious that the impacts of cyberbullying need to be further addressed, that measurement issues need to be investigated and that the relationships between cyberbullying and typical background variables assessed. Furthermore, many analytical approaches to assess bullying in general are sensitive to measurement error. It is important to gain knowledge about the magnitude of measurement error to be able to evaluate possible bias related to this problem. This study aims to deal with these issues within the limits of the available data.

On the basis of presented theory, we set out some basic hypotheses and some research questions. The basic hypotheses are derived from known relationships between gender, SES and academic achievements. These hypotheses are included to provide some evidence for construct validity, provided that they produce results as expected.

Hypotheses:

- Girls perform better than boys academically

- SES is not correlated with gender (gender being random across SES), but with academic achievement

\section{Research questions}

- Are there differences in impact on academic achievements between cyberbullying and cyber harassment, and between cyber and traditional harassment (verbal, physical and social)?

- Are there gender differences in terms of victimisation of cyberbullying and cyber harassment?

- What degrees of error exist in the measures of cyber- harassment and cyberbullying? 
- How does SES influence cyber harassment and -bullying?

The many factors that influence academic achievement include motivation, talent, teacher support and so on. Hattie (2008) assessed and ranked 138 factors, but even that list is probably not exhaustive. The models used in our study are simple and straightforward. This makes them easy to interpret, but it is important to bear in mind that any variable included in or omitted from a model will have an impact on the parameters, sometimes to such a degree that its conclusions may have to be changed.

\section{Methods}

As we pointed out in the Background section, it is not obvious whether one should use global items as is often done in the assessment of traditional bullying, or take an alternative approach to measuring the prevalence of specific instances of negative online behaviour (Livingstone and Smith, 2014). The present study adopts the two approaches to capturing cyberbullying. While one approach builds upon the use of global items (Solberg and Olweus, 2003, Olweus, 2013), the other utilize items of observable behaviour (Arora, 1996). Kowalski et al. (2014) provide a thorough review of these approaches.

\section{Participants}

878 pupils (age 9-16) at five schools in the city of Troms $\varnothing$ in Northern Norway participated. The response rate was $66,5 \%$. The gender mix was 50/50. Indicators of age, socio-economic status, academic achievement and sex were collected. No ethnic/race indicators were collected.

\section{Procedure}

Data were acquired in November-February 2013/-14 through an online questionnaire administered by class teachers, and the students completed the questionnaire during school hours. Feedback from teachers indicates that most students completed the survey within 30 minutes, and that they appeared to be well-motivated.

\section{Ethics}

Ethics is a challenging issue for the "Well-being in Tromsø" project, of which this study forms a part. Not only are many of the data of a sensitive nature, as they cover topics like mental health, harassment, bullying and well-being (QoL), but identification information is even included. Students and parents were informed about the project in class meetings and by letter, and written parental consent to participate was obtained. All respondents are anonymised and identification keys are stored safely. The project was approved by the Regional Ethics Committee (REK) in 2012.

\section{Measure}

The student questionnaire consists of 33 items from the "Strengths and difficulties Questionnaire" (SDQ) (Goodman, 1997), 24 items from the KINDL instrument (RavensSieberer and Bullinger, 1998), 15 items regarding traditional harassment (Rønning et al., 2004), eight new cyber harassment items, ten bullying (global) items, six items concerning perception of intervention in bullying incidents, items on gender involvement, items regarding background variables such as number of books at home 
and parental level of education. Only a few background variables were included due to the length of the questionnaire, and in order to avoid stressing the pupils. This part of the study does not make use of SDQ and only a part of KINDL.

Academic skills were measured through a single question given to the teachers: "The student is proficient in language, mathematics and foreign language". The teachers choose one of three response categories: "Completely true", "partly true" or "not true".

Socioeconomic status (SES) was measured via a single item: "How many books do you have at home?" (Marks et al., 2006). Five categories are available: "1-10", "11-25", "26$100 "$, "101-250" "more than 250".

The 15 items of traditional harassment (verbal, physical and social) and the 8 items of cyber harassment formed the basis for most of the analyses in the study. The traditional harassment inventory consists of 15 items from the Arora "Life in School Checklist" (Arora, 1994). These items were selected by Rønning, Handegaard and Sourander (2004). In addition to these 15 items on traditional harassment, eight new items on cyber harassment were included, based on constructs by Smith, Mahdavi, Carvalho \& Tippett (2006) and Menesini, Nocentini \& Calussi (2011).

Measuring cyberbullying is not a straightforward process. Two global items measure cyberbullying at school and at home during the last two or three months. However, cyberbullying is part of a general bullying construct, of which traditional bullying is also part. As two manifest items are not optimal in terms of achieving model identification, the two global general bullying (bullied at school or at home) items are included in the model. Parameter estimates of the model enabled us to compare these two forms of bullying. The items are kept with full information (no dichotomization or other transformation). Response categories are for all items "Never", "Only once or twice", "Two or three times a month", "About once a week" and "Several times a week".

Quality of life at school (QoLsch) was measured by the four items ("During the last week in which I was at school..."): "...doing my schoolwork was easy", "...I enjoyed my lessons", "...I worried about my future" and "...I worried about bad marks or grades". Response categories are "Never", "Seldom", "Sometimes", "Often" and "All the time". The scores for the last two items are reversed in the analysis.

\section{Analysis}

Measurement error was calculated as one minus the square of a manifest indicator's factor loading and is given by Mplus. A large measurement error would normally mean that the indicator is not ideal in its ability to capture the latent trait. Measurement error can create considerable bias if not taken into account, but this issue can largely be resolved by the use of SEM models. Both the cyber harassment and cyberbullying models were assessed for measurement error. In the case of cyberbullying, two global cyberbullying items were supplemented by two global items of traditional bullying in order to achieve model identification. Indicator error was correlated for the two cyber items and likewise for the two traditional items.

The impact of cyber harassment, socio-economic status and gender on academic skills is assessed through the use of structural equation modelling in the form of path analysis. 
The eight indicators of cyber harassment load onto a single latent factor, as do the indicators of verbal, social and physical harassment. Academic skills and SES form single-item latent factors. QoLsch is measured by four items. Gender is also included. Similarly, two global manifest indicators of cyberbullying load onto a single latent factor, while keeping the other variables and factors.

In models that include single-item measures (e.g. models $1 \mathrm{a}-\mathrm{d}$ and 2 in Table 2) the errors of the items were estimated using the formula (1-reliability)*sample variance (Wang and Wang, 2012, p. 130). Estimating the error and fixing the loading at 1 enabled us to make the measure latent. The reliability of the two relevant items, academic performance and socioeconomic status, was estimated by means of a test-retest approach from two waves (years one and two).

\section{Results}

All results concerning model fit are given in the technical appendix along with methodological issues. Models for traditional harassment are also presented in the technical appendix, but referred to in the following text.

The results are derived from eight models. Models $1 \mathrm{a}, \mathrm{b}, \mathrm{c}, \mathrm{d}$ are recursive path models in which the impact of harassment on academic achievement is assessed. The models also include measures of SES, gender and quality of life at school (QoLsch). Model 2 is similar to model $1 \mathrm{a}-\mathrm{d}$, but harassment factors is replaced by a cyberbullying factor. Model 3 is a basic, single-factor confirmatory model, in which eight items load onto a latent factor. The model is used to assess measurement error. Model 4 is similar to model 3, but the model consists of four global bullying items, which loads onto a latent factor. Models 3 and 4 are used to evaluate measurement error in the bullying construct.

\section{Hypotheses}

The present study set out some hypotheses to help identifying possible problems with the models. For the evaluation of these basic assumptions we refer to the cyber harassment model. Model parameters are standardized (stdyx) and only significant values are referred to throughout the text. First, it is assumed that girls perform better at school than boys. In our sample and using our measures, girls do indeed perform somewhat better than boys ( $\mathrm{r}=-.21$ where girls are coded "1", boys "2"). Second, it was assumed that SES is not logically associated with gender, and this assumption holds with a correlation of .01 (not shown in the model). Third, as expected, SES is positively related to academic achievement and the size of the relationship is significant and moderate $(r=.28)$. These basic assumptions are not related to whether we choose a model based on the construct of cyberbullying or cyber harassment; the figures are the about same for both approaches.

Model 1a shows the relationships between cyber harassment, quality of life at school and academic achievements, but also impact of background variables. 


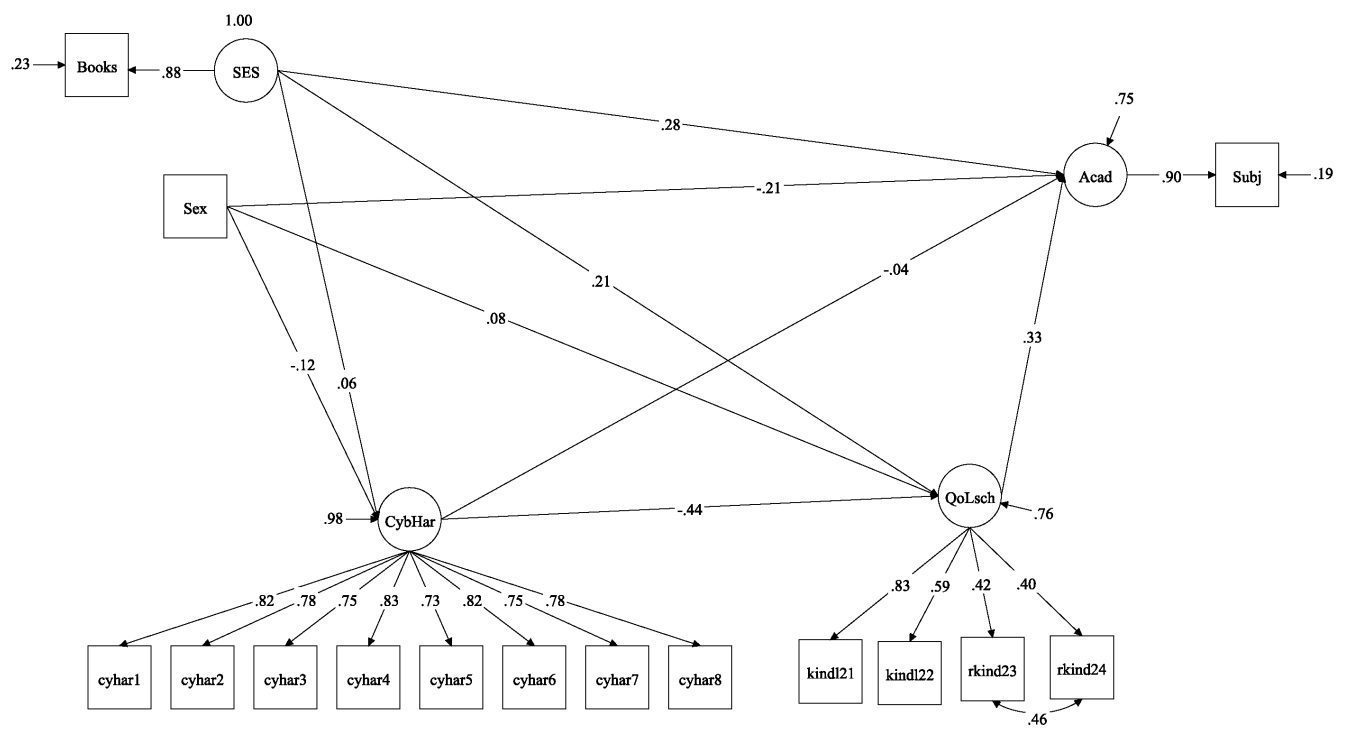

Model 1a: Cyber harassment. Recursive path model. All parameters are standardized (stdyx) and significant at the .05 level. Factors are: gender (Sex), cyber harassment (CybHar), QoL at school (QoLsch), academic achievement (Acad) and SES (SES).

Model 2 is similar to model 1a, but the construct of cyber harassment is replaced with cyberbullying.

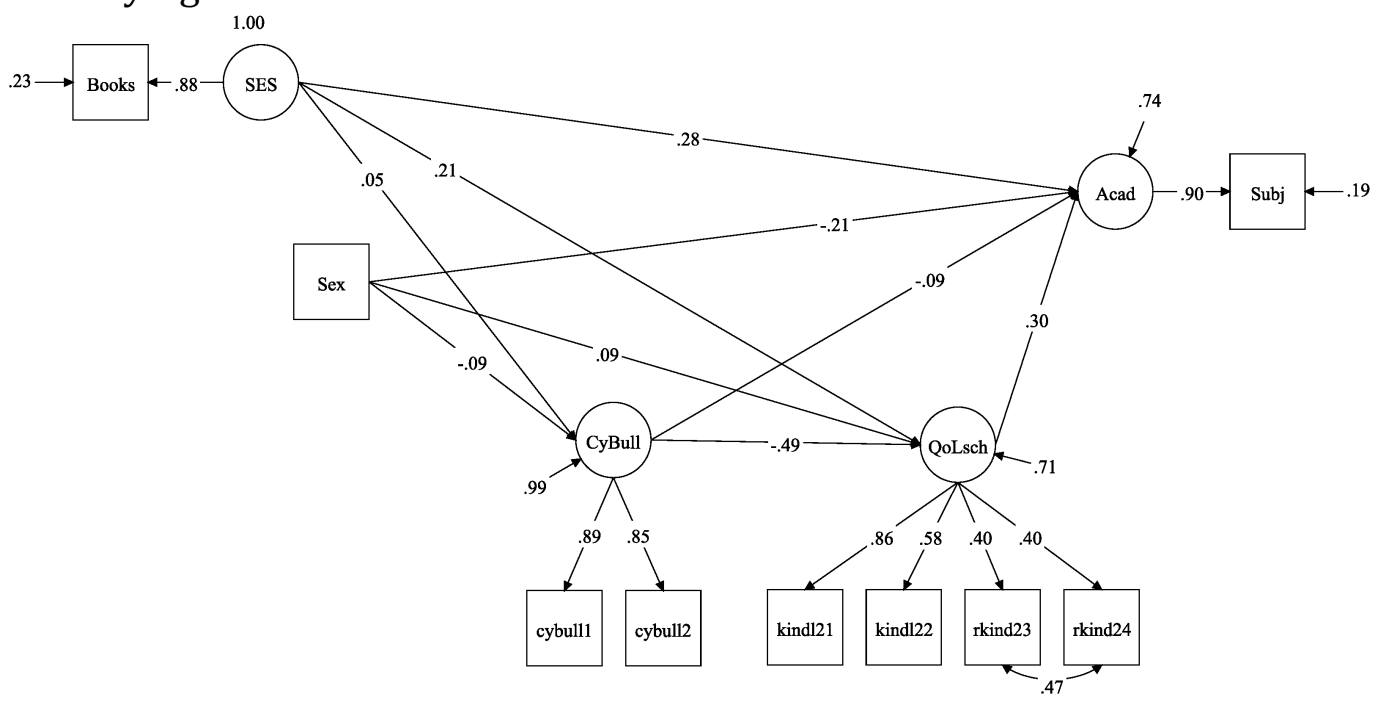

Model 2: Cyberbullying. Recursive path model. All parameters are standardized (stdyx) and significant at the .05 level. Factors are: gender (sex), cyberbullying (CyBull), QoL at school (QoLsch), academic achievement (Acad) and SES (SES).

\section{Effects of cyberbullying and the four kinds of harassment}

Models $1 \mathrm{a}$ and 2 show parameter estimates for recursive models including four latent factors (academic achievements, SES, QoLsch and cyber harassment (model 1a) or cyberbullying (model 2) and one manifest variable (gender). In a preliminary model in which the QoLsch construct was omitted, differences were found in the strength of the predictions of cyberbullying and harassment on academic achievements. Bullying items produced a marginally larger effect $(r=-.21)$ than the harassment items $(r=-.18)$. In the model that included the QoLsch construct, cyberbullying and cyber harassment produce very low direct effects on academic achievements $(r=-.04$ and -.09 for harassment and 
bullying respectively). However, both models displayed a significant and substantial negative effect on QoLsch ( $\mathrm{r}=-.44$ and $\mathrm{r}=-.49$ for harassment and bullying respectively). QoLsch has a moderate and positive impact on academic achievement, $r=.33$ for cyber harassment and .30 for cyberbullying. However, the effects of cyber harassment and cyberbullying on academic achievements include both direct and indirect effects. The indirect effect is mediated through QoLsch. There are not very large differences between the four forms of harassment in terms of effect on academic achievements, but cyberbullying seems to yield a somewhat stronger effect than what the four kinds of harassment do (table 1).

Table 1: Direct and indirect effects of harassment on academic achievements

\begin{tabular}{llll}
\hline & Direct effect & Indirect effect & Total effect \\
\hline M2: Cyberbullying & -.090 & -.147 & -.237 \\
M1a: Cyber harassment & -.020 & -.144 & -.164 \\
M1b: Verbal harassment & .001 & -.165 & -.164 \\
M1c: Social harassment & -.055 & -.130 & -.185 \\
M1d: Physical harassment & -.115 & -.090 & -.205 \\
\hline
\end{tabular}

Effects of cyberbullying and four forms of harassment on academic skills. Indirect effects are mediated through quality of life at school (QoLsch). Total effect $=$ direct effect + indirect effect. SEM models $1 \mathrm{~b}, \mathrm{c}$ and $\mathrm{d}$ are presented in the technical appendix.

There is an effect of cyberbullying and the four forms of harassment on academic skills, total effects ranging from -.164 for verbal and cyber harassment to - .237 for cyberbullying. In most cases it is the indirect effect that dominates, except for the case of physical harassment where the direct effect is somewhat larger than the indirect.

\section{Sex differences in bullying victimisation}

From theory it was unclear whether girls or boys are most involved in cyberbullying. In our sample, and using our measures, girls are actually more likely to be victims of cyber harassment than boys ( $\mathrm{r}=-.12)$. For the model of cyberbullying, the effect is the opposite $r=.09$. The differences, although significant, are small.

\section{Measurement error}

Measurement error was estimated in the two basic factor models (models 3 and 4). For the eight-item single latent factor model of cyber harassment, the items explain $60.8 \%$ of the variance. The remaining $39.2 \%$ of the combined variance of the indicators is related to measurement error, either in the form of random or systematic error. The four items in the single latent factor model of bullying explain $64.4 \%$ of the variance, leaving $35.6 \%$ for the combined indicator error. However, the two items of cyberbullying produce a much greater error than the two items that refer to traditional bullying; $49.5 \%$ error for cyberbullying compared to $21.1 \%$ for the two traditional items. All in all, there is a significant amount of measurement error whether we use manifest instances of negative cyber behaviour or global items of cyberbullying.

\section{The influence of SES on cyberbullying and cyber harassment, academic achievement and relationship to gender}

SES does not predict either cyberbullying or cyber harassment $(r=.05$ and $r=.06$ for cyber harassment and cyberbullying respectively). SES predicted academic achievement moderately $(\mathrm{r}=.28)$. 


\section{Discussion}

Both hypotheses are confirmed. Based on presented theory and logic, we expected to find an impact of gender on academic achievement, an impact of SES on academic achievement and no association between gender and SES. Girls do somewhat better than boys academically, according to their teachers who rated their overall performance in core subjects, but the difference is not large ( $\mathrm{r}=-.21)$. The effect of SES on academic achievement is moderate $(\mathrm{r}=.28)$ and of a similar size to that found in the literature (Sirin, 2005, White, 1982). We found no relationship between sex and SES, as one would logically expect ( $\mathrm{r}=.01)$. As all these basic hypotheses are met, some evidence for the validity of our constructs is found. The models seem to produce results as expected for the variables where prior results are available. However, both the SES variable and the academic skills variable (assessed by the teacher) consist of only one indicator.

Generally one is advised not to use single indicator approaches as reliability normally is threatened. However, as the questionnaires consisted of about 100 items, there was little room to include background variables at all. Typically the SES measures yield correlations to academic skills of about .30 (White, 1982). Our models produce very similar results (.28). This finding gives some indication that the variables are reliable.

Cyberbullying and cyber harassment have a negative influence on academic achievement. In an initial model that did not include quality of life at school (QoLsch), the effect was negative and of similar, small to moderate, size for both cyberbullying and cyber harassment ( $\mathrm{r}=-21$ and $\mathrm{r}=-18$, accordingly). When QoLsch is included in both the models, the effect of cyberbullying and cyber harassment almost vanishes, but a strong impact on QoLsch can be seen. This implies that QoLsch mediates the effect of bullying or harassment onto academic achievement. Indeed, when mediation is accounted for in the SEM model, indirect effects of cyberbullying and harassment are seen in all models. Children reporting cyberbullying or cyber harassment are likely to experience lower quality of life at school, resulting in lowered school performance. Moreover, QoLsch moderately predicts academic achievements in all models of cyberbullying and harassment ( $\mathrm{r}=.30, \mathrm{r}=.35$, respectively). It is likely that being harassed in any form has a negative impact on well-being at school, as a result of which, academic performance decreases. There is little difference between the four kinds of harassment, but physical harassment seems to have the strongest, negative impact on academic achievements. However, alternative models with other variables could produce a different result, so there is need to investigate this finding further.

The prevalence estimates for cyberbullying is much lower than for cyber harassment, $3.5 \%$ compared to $6.6 \%$, probably indicating that the cyber harassment items are capturing incidents that do not qualify as bullying. In other words, the cyberbullying items are probably capturing more severe kinds of peer aggression. Interestingly, the effect on academic achievement and quality of life at school do not differ between the two approaches. Logically, one would expect more severe kinds of aggression to have greater impact on school performance and well-being than less severe kinds. This does not seem to be the case. As this study is cross-sectional, it is not possible to assess issues like the long-term effects of bullying on academic achievements. The effects of bullying on academic performance are probably not immediate, but a result of long-term victimization. Researchers have identified several mediating factors involved in the 
impact of bullying on academic achievements, but much still remains to be studied in this field (Nakamoto and Schwartz, 2010).

Typically in factor analysis the researcher loads a number of indicators onto one or more factors. The factor loadings should be as high as possible. The amount of variation not captured by the factor(s), often labelled indicator residual, uniqueness or error, might cause problems in the analysis. Measurement error is substantial for both our models of cyber harassment and cyberbullying. For the harassment inventory, $39.2 \%$ of the variance of the indicators is actually measurement error. Where cyberbullying is concerned, the total error variance for the four bullying items added up to $35.6 \%$, but the two cyberbullying items yielded about twice as much error than the two traditional ones did. All in all, whether we use manifest indicators that measure cyber harassment or global items measure cyberbullying, the measurement error is substantial. Cote and Buckley (1987) found that abstract constructs tend to produce greater measurement error than concrete ones. Bullying is a rather abstract term, as it might be regarded as a subcategory of peer aggression distinguished by the criteria of repetition/duration, intention to harm and an imbalance of power. Obviously, assessments of these criteria are rather subjective. In contrast, the cyber harassment items relate to concrete types of negative behaviour typically encountered on computer, mobile phone or other digital platforms. As many reports on bullying in fact rely on methods such as regressions analysis and ANOVA, which do not readily control for measurement errors, there is always a possibility of bias. It is sometimes difficult to assess whether researchers have taken measurement error into account if they do not state this specifically, give information about which estimator they used or if other error handling procedure has been employed. In the present article models are run within the SEM framework. As SEM models have measurement error estimated and taken out of the model, measurement error is no longer affecting model parameter. However, measurement error indicates how well the indicators capture the construct of interest. The lower the error the better. In our case the amount of error is moderate to high, especially for the two global items of cyberbullying.

SES does not appear to influence either cyberbullying or cyber harassment, with effects of only $r=.06$ and .05 respectively. The measure of SES used in this study (number of books at home) captured not merely the family's economic status, but rather a cultural aspect of the domestic environment (Marks et al., 2006). It seems that socio-cultural effects are poor predictors of cyberbullying or cyber harassment. In Norway, very few pupils live in poor homes, and 95\% of Norwegian students have access to technology, in most cases including social media (Medietilsynet, 2014). It has been found that the amount of time spent on the Internet predicts cyber aggression (Kowalski et al., 2014). If this is true in the present study too, it might indicate that there is little difference between children from different homes in terms of online practise. The fact that SES seems not to predict whether children are exposed to cyberbullying or not indicate less need to control for this factor. However, more needs to be done in this respect, both in terms of traditional and cyber forms of bullying and harassment.

Girls seem to be more cyber-harassed than boys, while boys seem to be more cyberbullied. But, the gender differences are indeed very small. The lack of substantial gender differences in prevalence does not necessarily mean that there are no differences in the concrete events girls and boys experience. 
The measurement of cyberbullying is problematic (Kowalski et al., 2014, Menesini and Nocentini, 2009). Lack of robust theory and definitions, a mix of different measurement approaches and the fact that cyberbullying consists of a wide range of ever-changing types of negative behaviour are some of the issues that researchers struggle with. Furthermore, from research on traditional bullying, we have learned that students perceive bullying differently from teachers (Stockdale et al., 2002, Naylor et al., 2006), and that younger children tend to include a wider range of negative conduct than their older peers (Frisen et al., 2008). These issues are probably not less substantial in the context of cyberbullying. Furthermore, there is an obvious subjective factor involved when defining a specific act as bullying. What one child clearly state as bullying another would not. And the range of negative conducts involved in bullying are not equal in severity. For instance, Cheng et al. (2011) ranked the following items as most severe using Rasch analysis: "one's friendship being ruined", "being hit and kicked", "belongings taken without permission", "being ostracised" and "having humiliating photos posted online". Experience harassing photos published online is exclusively cyber, but children being subject to cyberbullying might often feel ostracised or have their friendship ruined. The question of how to best capture these aspects remains unanswered. These issues, but probably several more, indicate that instruments need to be developed further, and methods of data collection need to be improved. Theory and definitions must also be further developed. The precision of the two inventories included in the present study is probably less than optimal. The cyber harassment inventory needs more work to develop more precise items that better represent the construct of cyber harassment. Olweus (2013) suggests using a general global item to capture the concept of bullying. Researcher could then include concrete forms of negative behaviour to distinguish between the different types of bullying. Our approach employed two global items to capture cyberbullying, but as these items are liable to a substantial amount of error that is even greater than the items concerning concrete forms of harassment, this approach can be questioned. Further investigation is needed to validate the global item approach to capturing cyberbullying.

\section{Conclusions and further research}

Cyberbullying and online harassment are among the activities that children are involved in that negatively impact on well-being at school and academic achievement. In the present study, most cyberbullying take place at home $(1.2 \%$ report being cyberbullied at school compared to $3.4 \%$ at home), but problems are seen at school as well. It is important that schools are able to effectively prevent cyberbullying, but also that they are able to take actions when such events occur. It is challenging to intervene in bullying cases where the actions are taking place outside of school, indicating that cooperation between parents and teachers is crucial.

The basic hypotheses formulated in the present report were confirmed. Socioeconomic status is not related to gender, as one obviously would expect, but is significantly and substantially related to academic achievement. There is no correlation between SES and cyberbullying or cyber harassment. Girls perform better academically, a finding that was as expected. We found very little evidence for gender differences in either bullying or harassment. Substantial measurement error was found in both cyberbullying and cyber harassment domains. Cyberbullying items seem to include more error than cyber 
harassment items. The expected impact of cyberbullying or harassment on academic achievement was not clearly identified. The effect was small to moderate in models where quality of life at school was omitted. In the models that included QoLsch, much of the effects of cyberbullying and cyber harassment on academic achievements were mediated through QoLsch. There was no substantial difference between the cyberbullying and cyber harassment constructs in terms of predicting academic achievement.

The two constructs used here are probably not ideal, as they produce much error and struggle to pass the $\mathrm{X}^{2}$ test of absolute fit (see technical appendix). Further development should be made to produce ever more reliably items and scales. Researchers should consider measurement error when choosing analytical approach. Structural equation modelling would arguably solve many of the problems researchers face in this regard when working in the field of bullying research.

All in all, it appears that as far as predicting academic achievement is concerned, the cyber harassment model is superior to the cyberbullying model, as its measurement error is less than that of cyberbullying. However, even the cyber harassment approach needs to be improved, and the obvious problems of capturing the criteria that distinguish bullying from other forms of aggression also need to be dealt with in the context of cyberbullying. It is also necessary to study further why and to what extent victims of cyber-aggression perform worse at school.

\section{Limitations}

This study utilized cross-sectional data. This limits the possibility to make causal inferences, and long-term effects and relationships could not be assessed. Furthermore, the sample was drawn from five schools in a single city in Norway. A more representative sample would be needed to make robust generalizations. However, the Norwegian school is rather homogenous when it comes to academic standard (Nusche and et al.), making the selection of schools somewhat less important. It is also important to acknowledge that SEM models are sensitive to which variables are included or omitted. Parameter estimates might change when the model changes. Finally, the $\mathrm{X}^{2}$ values for most models are significant, indicating an unacceptable poorness of fit. However, as we point out in the technical appendix, the $\mathrm{X}^{2}$ test of absolute fit is sensitive to sample size. We argue that our models, although not perfect, are interpretable as other fit indices are acceptable or good. Nevertheless, more work need to be done to improve both the harassment and the bullying items. 


\section{Literature}

Arora, C. M. J. (1996). Defining Bullying: Towards a Clearer General Understanding and More Effective Intervention Strategies. School Psychology International, 17, 317 329.

Arora, T. (1994). Measuring Bullying with the "Life in School" Checklist. Pastoral Care in Education, 12, 11-15.

Bakken, A., Borg, E., Hegna, K. \& Backe-Hansen, E. (2008). Er det skolens skyld? En kunnskapsoversikt om skolens bidrag til kjønnsforskjeller i skoleprestasjoner. Oslo: Norsk Institutt for forskning om oppvekst, velferd og aldring.

Björkqvist, K., Lagerspetz, K. M. J. \& Kaukiainen, A. (1992). Do Girls Manipulate and Boys Fight? Developmental Trends in Regard to Direct and Indirect Aggression. Aggressive Behavior, 18, 117-127.

Brown, T. A. (2006). Confirmatory Factor Analysis for Applied Research. 2006. Confirmatory Factor Analysis for Applied Research. Xiii.

Campbell, M. A. (2005). Cyber Bullying: An Old Problem in A New Guise? Journal of Psychologists and Counsellors in Schools, 15, 68-76.

Cheng, Y.-Y., Chen, L.-M., Liu, K.-S. \& Chen, Y.-L. (2011). Development and Psychometric Evaluation of the School Bullying Scales: A Rasch Measurement Approach. Educational and Psychological Measurement, 71, 200-216.

Coleman, J. S., Campbell, E. Q., Hobson, C. J., Mcpartland, J., Mood, A. M., Weinfeld, F. D. \& York, R. L. (1966). Equality of Educational Opportunity. Washington: U.S. Department of Health, Education, and Welfare.

Cote, J. A. \& Buckley, M. R. (1987). Estimating Trait, Method, and Error Variance: Generalizing Across 70 Construct Validation Studies. Journal of Marketing Research, 24, 315-318.

Craig, W., Harel-Fisch, Y., Fogel-Grinvald, H., Dostaler, S., Hetland, J., Simons-Morton, B., Molcho, M., De Mato, M. G., Overpeck, M., Due, P. \& Pickett, W. (2009). A CrossNational Profile of Bullying and Victimization Among Adolescents in 40 Countries. International Journal of Public Health, 54, 216-224.

Erdur-Baker, 0. (2010). Cyberbullying and its Correlation to Traditional Bullying, Gender and Frequent and Risky Usage of Internet-Mediated Communication Tools. New Media \& Society, 12, 109-125.

Fekkes, M., Pijpers, F. I. M. \& Verloove-Vanhorick, S. P. (2004). Bullying Behavior and Associations with Psychosomatic Complaints and Depression in Victims. The Journal of Pediatrics, 144, 17-22.

Frisén, A. \& Bjarnelind, S. (2010). Health-Related Quality of Life and Bullying in Adolescence. Acta Pædiatrica, 99, 597-603.

Frisen, A., Holmqvist, K. \& Oscarsson, D. (2008). 13-Year-Olds' Perception of Bullying: Definitions, Reasons for Victimisation and Experience of Adults' Response. Educational Studies, 34, 105-117.

Glew, G. M., Fan, M., Katon, W., Rivara, F. P. \& Kernic, M. A. (2005). Bullying, Psychosocial Adjustment, and Academic Performance in Elementary School. Archives of Pediatrics \& Adolescent Medicine, 159, 1026-1031.

Goodman, R. (1997). The Strengths and Difficulties Questionnaire: A Research Note. Journal of Child Psychology and Psychiatry, 38, 581-586.

Grigg, D. W. (2010). Cyber-Aggression: Definition and Concept of Cyberbullying. Journal of Psychologists and Counsellors in Schools, 20, 143-156. 
Hattie, J. (2008). Visible Learning: A Synthesis Of over 800 Meta-Analyses Relating to Achievement, Routledge.

Heinemann, P.-P. (1973). Mobbing : Gruppevold Blant Barn Og Voksne, Oslo, Gyldendal.

Hu, L. T. \& Bentler, P. M. (1999). Cutoff Criteria for Fit Indexes in Covariance Structure Analysis: Conventional Criteria Versus New Alternatives. Structural Equation Modeling: A Multidisciplinary Journal, 6, 1-55.

Iacobucci, D. (2010). Structural Equations Modeling: Fit Indices, Sample Size, and Advanced Topics. Journal of Consumer Psychology, 20, 90-98.

Jozefiak, T. (2009). Quality of Life and Mental Health in Children and Adolescents: Child and Parent Perspectives. Phd Doctoral Thesis, Norges TekniskNaturvitenskapelige Universitet (NTNU).

Juvonen, J., Wang, Y. \& Espinoza, G. (2010). Bullying Experiences and Compromised Academic Performance Across Middle School Grades. The Journal of Early Adolescence.

Kowalski, R. M., Giumetti, G. W., Schroeder, A. N. \& Lattanner, M. R. (2014). Bullying in the Digital Age: A Critical Review and Meta-Analysis of Cyberbullying Research Among Youth. Psychological Bulletin, 140, 1073.

Kowalski, R. M. \& Limber, S. P. (2013). Psychological, Physical, and Academic Correlates of Cyberbullying and Traditional Bullying. Journal of Adolescent Health, 53, S13S20.

Lagerspetz, K. M. J., Björkqvist, K. \& Peltonen, T. (1988). Is Indirect Aggression Typical of Females? Gender Differences in Aggressiveness in 11- To 12-Year-Old Children. Aggressive Behavior, 14, 403-414.

Livingstone, S. \& Smith, P. K. (2014). Annual Research Review: Harms Experienced by Child Users of Online and Mobile Technologies: The Nature, Prevalence and Management of Sexual and Aggressive Risks in the Digital Age. Journal of Child Psychology and Psychiatry, 55, 635-654.

Marks, G. N., Cresswell, J. \& Ainley, J. (2006). Explaining Socioeconomic Inequalities in Student Achievement: The Role of Home and School Factors. Educational Research and Evaluation, 12, 105-128.

Marsh, H. W., Muthén, B., Asparouhov, T., Lüdtke, O., Robitzsch, A., Morin, A. J. S. \& Trautwein, U. (2009). Exploratory Structural Equation Modeling, Integrating Cfa and Efa: Application to Students' Evaluations of University Teaching. Structural Equation Modeling: A Multidisciplinary Journal, 16, 439-476.

Medietilsynet (2014). Barn og medier. Oslo: Medietilsynet.

Menesini, E., Fonzi, A. \& Smith, P. K. (2002). Attribution of Meanings to Terms Related to Bullying: A Comparison Between Teacher's and Pupil's Perspectives in Italy. European Journal of Psychology of Education, 17, 393-406.

Menesini, E. \& Nocentini, A. (2009). Cyberbullying Definition and Measurement: Some Critical Considerations. Zeitschrift Für Psychologie/Journal of Psychology, 217, 230-232.

Menesini, E., Nocentini, A. \& Calussi, P. (2011). The Measurement of Cyberbullying: Dimensional Structure and Relative Item Severity and Discrimination. Cyberpsychology, Behavior, and Social Networking, 14, 267-274.

Millsap, R. E. (2007). Structural Equation Modeling Made Difficult. Personality and Individual Differences, 42, 875-881.

Millsap, R. E. (2012). Statistical Approaches to Measurement Invariance, Routledge. Nakamoto, J. \& Schwartz, D. (2010). Is Peer Victimization Associated with Academic Achievement? A Meta - Analytic Review. Social Development, 19, 221-242. 
Naylor, P., Cowie, H., Cossin, F., De Bettencourt, R. \& Lemme, F. (2006). Teachers' and Pupils' Definitions of Bullying. British Journal of Educational Psychology, 76, 553576.

Nusche, D., . \& et l. (2011), Oecd Reviews of Evaluation and Assessment in Education: Norway, Oecd Publishing.

Oecd (2004). Pisa 2003 Learning for Tomorrow's World, Oecd Publishing.

Oecd (2007). Pisa 2006, Oecd Publishing.

Oecd (2010). Pisa 2009 Results: What Students Know and Can Do, Oecd Publishing.

Oecd (2014). Pisa 2012 Results: What Students Know and Can Do (Volume I, Revised Edition, February 2014), Oecd Publishing.

Oecd/Unesco (2003). Literacy Skills for The World of Tomorrow, Oecd Publishing.

Olweus, D. (1978). Aggression in the Schools: Bullies and Whipping Boys, Hemisphere.

Olweus, D. (1994). Annotation: Bullying at School: Basic Facts and Effects of a School Based Intervention Program. Child Psychology \& Psychiatry \& Allied Disciplines.

Olweus, D. (2001). Mobbing i skolen: Hva vet vi og hva kan vi gjøre?, Oslo, Gyldendal.

Olweus, D. (2013). School Bullying: Development and Some Important Challenges. Annu Rev Clin Psychol, 9, 751-80.

Ravens-Sieberer, U. \& Bullinger, M. (1998). Assessing Health-Related Quality of Life in Chronically Ill Children with the German Kindl: First Psychometric and Content Analytical Results. Quality Of Life Research, 7, 399-407.

Rønning, J. A., Handegaard, B. H. \& Sourander, A. (2004). Self-Perceived Peer Harassment in A Community Sample of Norwegian School Children. Child Abuse \& Neglect, 28, 1067-1079.

Salmivalli, C. \& Nieminen, E. (2002). Proactive and Reactive Aggression among School Bullies, Victims, and Bully-Victims. Aggressive Behavior, 28, 30-44.

Seals, D. \& Young, J. (2003). Bullying and Victimization: Prevalence and Relationship to Gender, Grade Level, Ethnicity, Self-Esteem, and Depression. Adolescence, 38, 735-747.

Sewell, W. H. \& Shah, V. P. (1967). Socioeconomic Status, Intelligence, and the Attainment of Higher Education. Sociology Of Education, 40, 1-23.

Siemsen, E., Roth, A. \& Oliveira, P. (2010). Common Method Bias in Regression Models with Linear, Quadratic, and Interaction Effects. Organizational Research Methods, $13,456-476$.

Sirin, S. R. (2005). Socioeconomic Status and Academic Achievement: A Meta-Analytic Review of Research. Review of Educational Research, 75, 417-453.

Smith, K., Avis, N. \& Assmann, S. (1999). Distinguishing Between Quality of Life and Health Status in Quality of Life Research: A Meta-Analysis. Quality of Life Research, 8, 447-459.

Smith, P., Mahdavi, J., Carvalho, M. \& Tippett, N. (2006). An Investigation into Cyberbullying, its Forms, Awareness and Impact, and The Relationship Between Age and Gender in Cyberbullying. Research Brief No. Rbx03-06. London: Dfes.

Smith, P. K., Cowie, H., Olafsson, R. F. \& Liefooghe, A. P. D. (2002). Definitions of Bullying: A Comparison of Terms Used, and Age and Gender Differences, In A FourteenCountry International Comparison. Child Development, 73, 1119-33.

Smith, R. G. \& Gross, A. M. (2006). Bullying: Prevalence and The Effect of Age and Gender. Child \& Family Behavior Therapy, 28, 13-37.

Smorti, A., Menesini, E. \& Smith, P. K. (2003). Parents' Definitions of Children's Bullying in a Five-Country Comparison. Journal of Cross-Cultural Psychology, 34, 417-432. 
Solberg, M. E. \& Olweus, D. (2003). Prevalence Estimation of School Bullying with the Olweus Bully/Victim Questionnaire. Aggressive Behavior, 29, 239-268.

Stevens, V., De Bourdeaudhuij, I. \& van Oost, P. (2000). Bullying in Flemish Schools: An Evaluation of Anti-Bullying Intervention in Primary and Secondary Schools. British Journal Of Educational Psychology, 70, 195-210.

Stockdale, M. S., Hangaduambo, S., Duys, D., Larson, K. \& Sarvela, P. D. (2002). Rural Elementary Students', Parents', and Teachers' Perceptions of Bullying. American Journal of Health Behavior, 26, 266-277.

Strøm, I. F., Thoresen, S., Wentzel-Larsen, T. \& Dyb, G. (2013). Violence, Bullying and Academic Achievement: A Study of 15-Year-Old Adolescents and their School Environment. Child Abuse \& Neglect, 37, 243-251.

Tokunaga, R. S. (2010). Following You Home From School: A Critical Review and Synthesis of Research on Cyberbullying Victimization. Computers in Human Behavior, 26, 277-287.

Vessey, J., Strout, T. D., Difazio, R. L. \& Walker, A. (2014). Measuring the Youth Bullying Experience: A Systematic Review of the Psychometric Properties of Available Instruments. Journal of School Health, 84, 819-843.

Vivolo-Kantor, A. M., Martell, B. N., Holland, K. M. \& Westby, R. (2014). A Systematic Review and Content Analysis of Bullying and Cyberbullying Measurement Strategies. Aggression And Violent Behavior, 19, 423-434.

Wang, J. \& Wang, X. (2012). Structural Equation Modeling: Applications Using Mplus, John Wiley \& Sons.

Wendelborg, C., Røe, M. \& Federici, R. A. (2014). Analyse av Elevundersøkelsen 2013. Trondheim: NTNU Samfunnsforskning.

White, K. R. (1982). The Relation Between Socioeconomic Status and Academic Achievement. Psychological Bulletin, 91, 461.

Wilkins-Shurmer, A., O'callaghan, M., Najman, J., Bor, W., Williams, G. \& Anderson, M. (2003). Association of Bullying with Adolescent Health-Related Quality of Life. Journal of Paediatrics and Child Health, 39, 436-441.

Woods, S. \& Wolke, D. (2004). Direct And Relational Bullying Among Primary School Children And Academic Achievement. Journal of School Psychology, 42, 135-155.

Yu, C.-Y. (2002). Evaluating Cutoff Criteria of Model Fit Indices for Latent Variable Models with Binary and Continuous Outcomes. University of California Los Angeles. 


\section{Technical appendix}

\section{Model fit}

We follow Brown (2006, p. 82) and report a variety of fit indices covering types of "absolute fit", "parsimony correction" and "comparative fit". Model fit is assessed through the use of the chi-square test of absolute fit $\left(\mathrm{X}^{2}\right)$, Root Mean Square Error of Approximation (RMSEA), the comparative fit index (CFI), the Tucker-Lewis index (TLI) and the weighted root-mean-square residual (WRMR). The $\mathrm{X}^{2}$ should be non-significant, but due to sensitivity to sample size this is often difficult (Iacobucci, 2010, Millsap, 2007). In the case of significant $X^{2}$, one should look for reasons for poor fit, evaluate other indices and provide a rationale if the model is used. For the other fit indices there are ongoing discussions about which cut-off should be used under the different conditions, such as small or large sample size, nominal or categorical data and the degree of normality of data (Marsh et al., 2009, Wang and Wang, 2012, Yu, 2002, Hu and Bentler, 1999). We used the following guideline cut-offs. RMSEA (good: <.06, acceptable: .08 ), CFI (good: $>.96$, acceptable: $>.90$ ) TLI (good: $>.95$, acceptable: .90), WRMR (acceptable: <.95).

Table 2

\begin{tabular}{|c|c|c|c|c|c|}
\hline Model & $\mathrm{X}^{2}$ & RMSEA & CFI & TLI & WRMR \\
\hline $\begin{array}{l}\text { Model 1a } \\
\text { Impact on academic achievement } \\
\text { (QoLsch, SES, gender and cyber } \\
\text { harassment) }\end{array}$ & $\begin{array}{l}172.519 \\
(\mathrm{df}=84, \mathrm{p}<.001)\end{array}$ & $\begin{array}{l}.035(.027- \\
.042, \mathrm{p}=1.00)\end{array}$ & .972 & .965 & .990 \\
\hline $\begin{array}{l}\text { Model 1b } \\
\text { Impact on academic achievement } \\
\text { (QoLsch, SES, gender and verbal } \\
\text { harassment) }\end{array}$ & $\begin{array}{l}118.898 \\
(d f=47, p<.001)\end{array}$ & $\begin{array}{l}.042(.033- \\
.051, p=.924)\end{array}$ & .985 & .980 & .880 \\
\hline $\begin{array}{l}\text { Model 1c } \\
\text { Impact on academic } \\
\text { achievement(QoLsch, SES, gender and } \\
\text { social harassment) }\end{array}$ & $\begin{array}{l}188.957 \\
(d f=58, p<001)\end{array}$ & $\begin{array}{l}.051(.43-.059 \\
\mathrm{p}=428)\end{array}$ & .973 & .964 & 1.076 \\
\hline $\begin{array}{l}\text { Model 1d Impact on academic } \\
\text { achievement (QoLsch, SES, gender and } \\
\text { physical harassment) }\end{array}$ & $\begin{array}{l}51.221(\mathrm{df}=37 \\
\mathrm{p}=.060)\end{array}$ & $\begin{array}{l}.021(.000- \\
.0034, \mathrm{p}=1.00)\end{array}$ & .995 & .992 & .637 \\
\hline $\begin{array}{l}\text { Model } 2 \\
\text { Impact on academic achievement } \\
\text { (QoLsch, SES, gender and cyberbullying) }\end{array}$ & $\begin{array}{l}57.686 \\
(\mathrm{df}=20, \mathrm{p}<.001)\end{array}$ & $\begin{array}{l}.046(.033- \\
.061, p=.644)\end{array}$ & .976 & .956 & .816 \\
\hline $\begin{array}{l}\text { Model } 3 \\
\text { Cyber harassment ( } 8 \text { items on } 1 \text { factor) }\end{array}$ & $\begin{array}{l}57.021 \\
(\mathrm{df}=20, \mathrm{p}<.001)\end{array}$ & $\begin{array}{l}.046(.032- \\
.060, p=.661)\end{array}$ & .978 & .969 & .765 \\
\hline $\begin{array}{l}\text { Model } 4 \\
\text { Bullying ( } 4 \text { bullying items on } 1 \text { factor) }\end{array}$ & $(d f=1, p=.001)$ & $\begin{array}{l}.080(.032- \\
.143, p=.136)\end{array}$ & .996 & .978 & .290 \\
\hline
\end{tabular}

Results of model fit. Models $1 \mathrm{a}, \mathrm{b}, \mathrm{c}, \mathrm{d}$ and 2 are recursive path models. Models 3 and 4 are single-factor confirmatory models (CFA).

\section{Model fit results}

Table 1 shows information regarding model fit for four SEM models. Two items regarding QoLsch are correlated as they both deal with future worries and are indicated in the model output to be correlated. Academic achievement was measured with a fixed error of .113, and SES with a fixed error of .300, based on estimated reliability. Most models struggle with the $\mathrm{X}^{2}$ test. Model $1 \mathrm{~d}$ passes and Model 4 is close to the .01significance level. However, $\mathrm{X}^{2}$ is sensitive to sample size (Millsap, 2012, Millsap, 2007, Marsh et al., 2009), and for this reason it is useful to assess the other indices of 
goodness, and then try to identify the misfit that might cause $\mathrm{X}^{2}$ to become significant. For all four models the indices of fit were acceptable or good. The RMSEA for Model 4 is on the borderline (and with a large confidence interval) of what is often regarded as acceptable, while the other indices of fit were good. For Model 1a and 1c, the WRMR are just outside the .95-level (.99/1.08), but the other fit indices are good. The modification indices either point at the cyber harassment items, or the bullying items are sources of poor fit. Item residuals are correlated for several items, indicating that some items share common variance that is not accounted for by the common factor. A model with more than one factor might have improved the model, but for both models principal component analysis indicates a one-factor model. In theoretical terms the single-factor model is best defensible. With acceptable to good values for all the other fit indices we conclude that the models are interpretable, but the items should probably be developed further.

Model 1b. SEM path model for verbal harassment

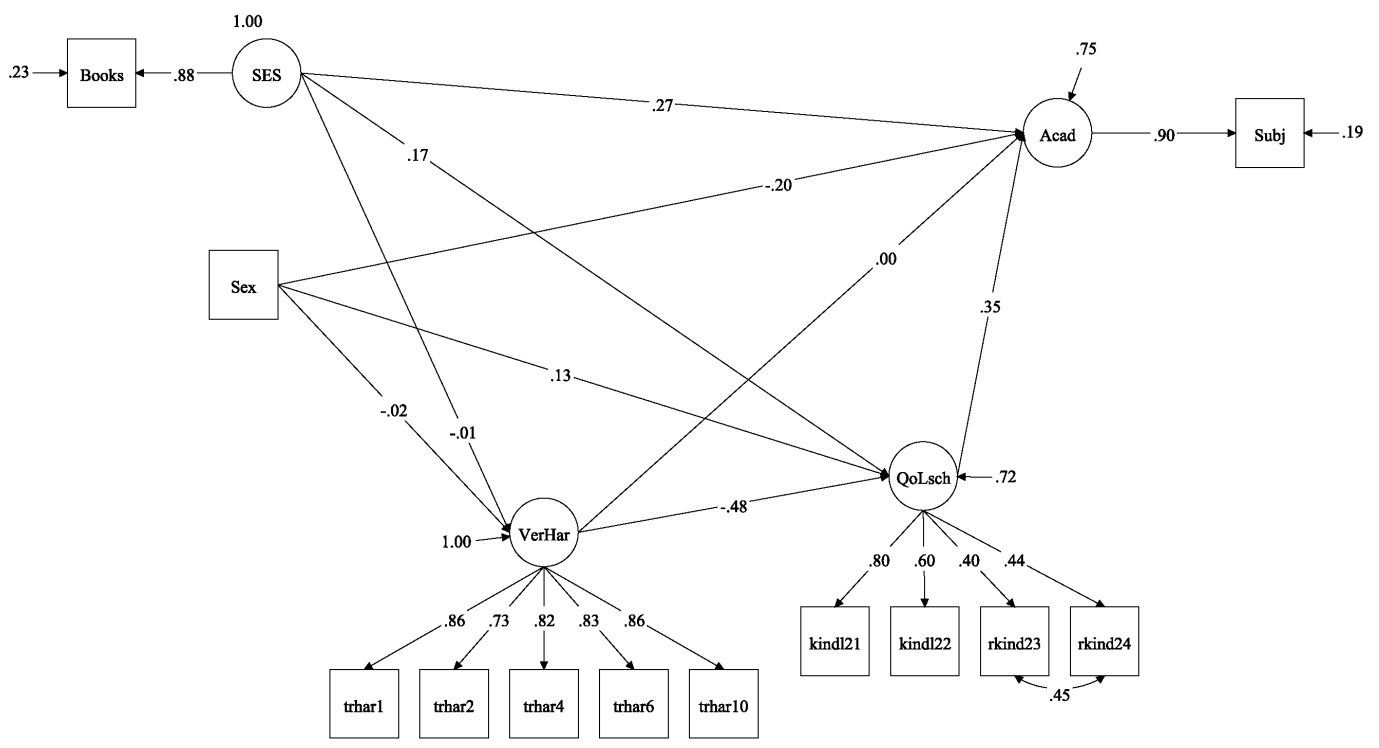

Model 1c. SEM path model for social harassment 


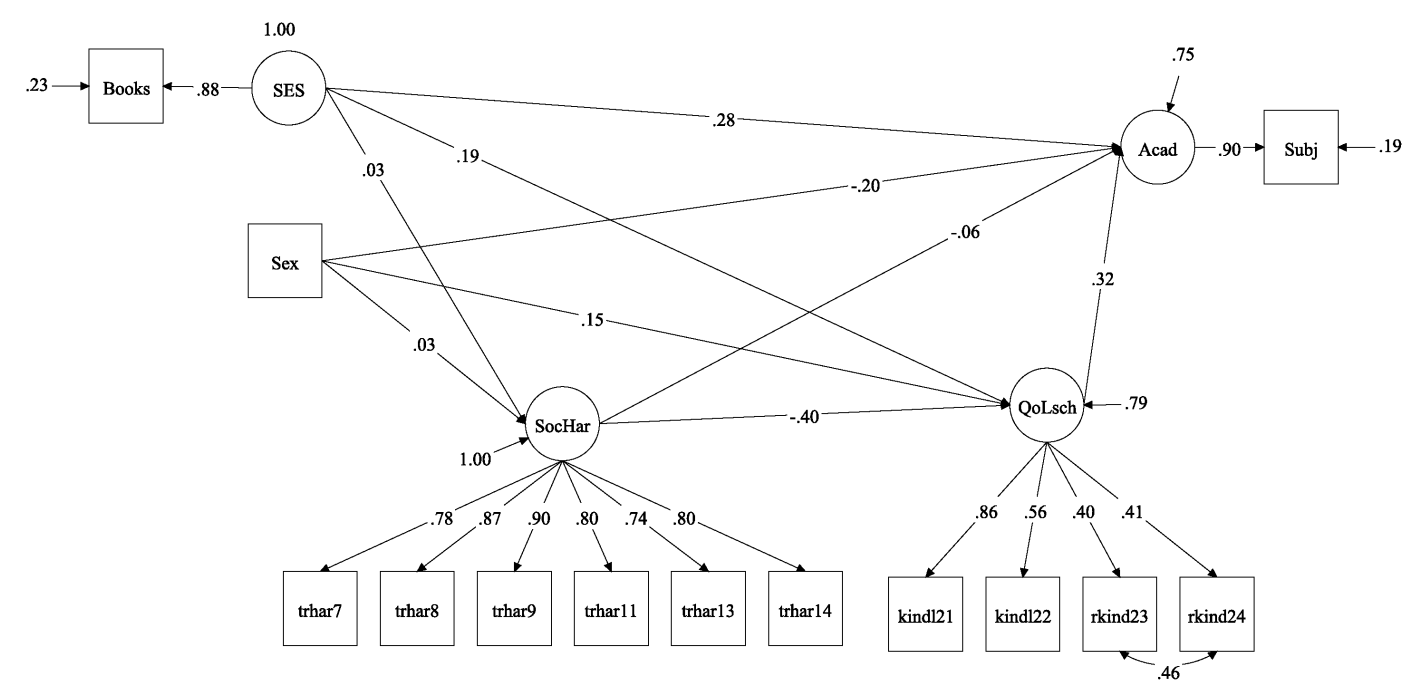

Model 1d. SEM path model for physical harassment

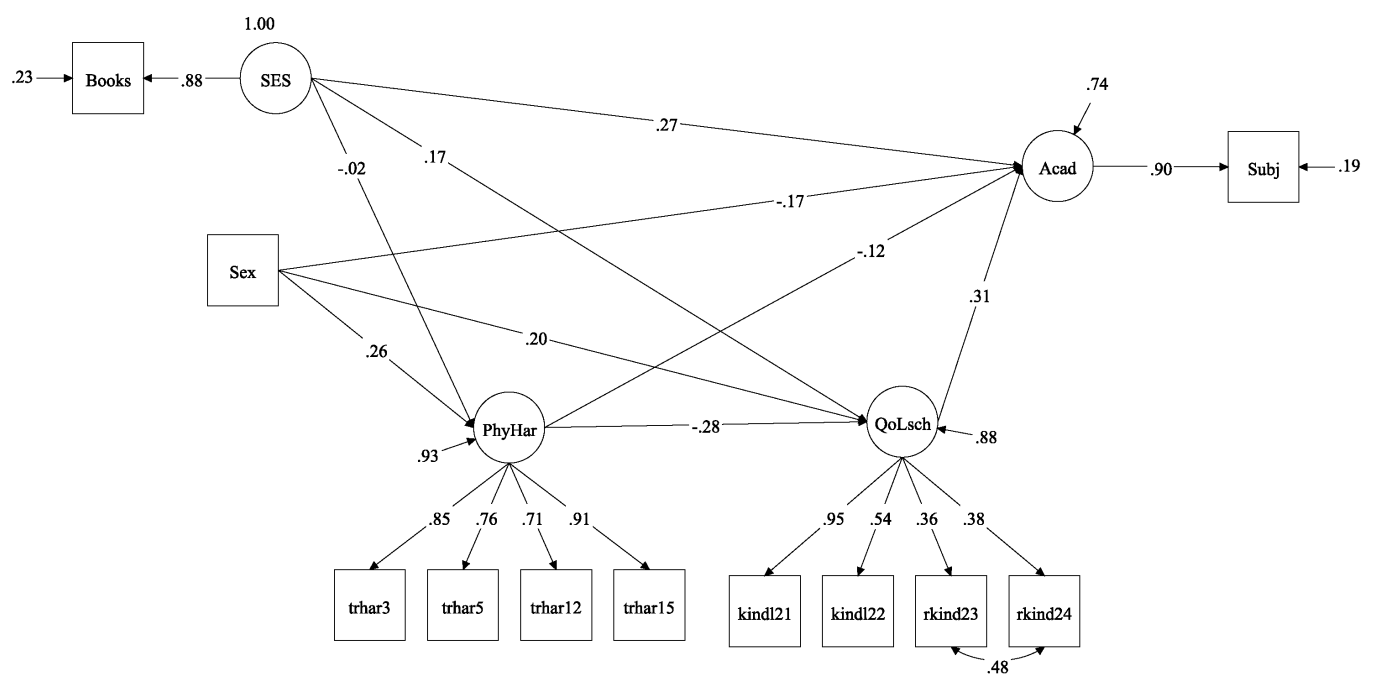

